\title{
Article
}

\section{Social Media and Mediation of Childbirth: So, What for Mothers, Maternity, and Midwifery Practice?}

Tizard, Hannah Rachel and Pezaro, Sally

Available at http://clok.uclan.ac.uk/31277/

Tizard, Hannah Rachel and Pezaro, Sally (2019) Social Media and Mediation of Childbirth: So, What for Mothers, Maternity, and Midwifery Practice? International Journal of Childbirth, 9 (2). pp. 69-79. ISSN 2156-5287

It is advisable to refer to the publisher's version if you intend to cite from the work. http://dx.doi.org/10.1891/2156-5287.9.2.69

For more information about UCLan's research in this area go to http://www.uclan.ac.uk/researchgroups/ and search for < name of research Group>.

For information about Research generally at UCLan please go to http://www.uclan.ac.uk/research/

All outputs in CLoK are protected by Intellectual Property Rights law, including Copyright law. Copyright, IPR and Moral Rights for the works on this site are retained by the individual authors and/or other copyright owners. Terms and conditions for use of this material are defined in the policies page. 


\title{
Social Media and the Mediation of Childbirth: So, What for Mothers, Maternity, and Midwifery Practice?
}

\author{
Hannah Tizard and Sally Pezaro
}

\begin{abstract}
Social media is fast becoming a global phenomenon with recent research providing insight into the complex inter-weaving relationship between the media and women and families over the childbirth continuum. Additionally, a growing body of evidence demonstrates a major cultural shift in the agency and information-seeking practices of women through social media. This perhaps suggests that services fall short of providing real and lived value to the women navigating through maternity systems in the United Kingdom, due to changes in culture and society. A deeper understanding of this phenomenon may help providers and practitioners offer care which better supports women's needs and enable them to develop innovative new approaches for future service provision. The aim of this article is to examine the literature and develop a deeper understanding of how social media may impact upon women, childbearing and midwifery practice via six domains. In conclusion, informational, experimental, and relational needs of women could be enhanced with funding and investment into the role of new expert tech-midwives using social media initiatives within maternity systems. Thus, supporting the demands of modern technology use by woman to elevate midwifery care provision and satisfaction and protect against the technocratic and patriarchal influence of childbirth. This synthesis of the literature through a western cultural lens may also be relevant to an international audience.
\end{abstract}

KEYWORDS: Social media; midwifery practice; information seeking; relational care; social construction; Web 2.0

\section{INTRODUCTION}

Excellence in care, clinical outcomes, and patient experience are the ultimate goals of modern-day healthcare (Department of Health [DH], 2016). Midwifery care is located firmly within a feminist framework of womancenterd principles. These promote the views, beliefs, and values of women and families to support informed decision-making in relation to pregnancy and birth, in partnership with healthcare professionals (Cumberlege, 2016; International Confederation of Midwives, 2013; National Institute for Health and Career Excellence [NICE], 2014; Nursing and Midwifery Council [NMC], 2018; Royal College of Midwives, 2014; World Health Organization, 2018). Provision of evidence-based healthcare information is fundamental to achieving these aims. While provider use of social media to help deliver this information is increasing, this may often be a one-way linear process, despite social media's potential to enable individualized conversational interaction to women. Web 2.0 is defined as the second phase of Internet evolution, characterized principally by "the change from static web pages to dynamic user-generated content and the growth of social media" (Web 2.0,2019).

The worldwide digital population as of 2019 demonstrates over 4.4 billion people were active Internet users and 3.5 billion were social media users (Statista, 2019a). Data identifies over two billion active monthly users on Facebook and 1.9 billion active monthly users on YouTube's video streaming platform (Statista, 2019b). Phillippi and Buxton (2010) identify Web 2.0 as an unparalleled entity of common tools providing access to 
information through an interconnecting network, transforming methods of communication, interaction, and content creation. Wikipedia ranked fifth most popular website on Google is an example of a type of social media where knowledge is constantly and collaboratively expanded by anonymous actual or self-proclaimed expert users to create general reference material (Benkler, 2011). While some may challenge the credibility of information on this Commons Based Peer Production (CBPP) model website, Internet users value its offering (Kittur, Suh, \& Chi, 2008; Lucassen \& Schraagen, 2010). Benkler's CBPP concept can also be widely applied to many innovative and developing grassroots movements in maternity healthcare, one such example being The Positive Birth Movement (Hill, 2017).

At the end of quarter 3 in 2017, 95\%-100\% of females aged 15-44 had access to the Internet, with $86 \%-95 \%$ having a smartphone (Jain, Koray, Carpenter, \& Roe, 2017). Social media provides endless opportunities for women and families navigating the transition to parenthood (Fleming, Vandermause, \& Shaw, 2014; Gibson \& Hanson, 2013; Lupton, 2016) via discussion forums (Johnson, 2014; Pedersen, 2014; 2016), blogs (Das, 2017; Dekker, King, \& Lester, 2016; Johnson, 2014; Ventola, 2014), social network platforms (Das, 2017), and more recently, video media, apps, and podcasts (Frizzo-Barker \& Chow-White, 2012; Hearn, Miller, \& Fletcher, 2013; Lupton \& Pedersen, 2016). For example, Wallwiener et al. (2016) note that primigravid women and first-time mothers are more likely to use Web 2.0 tools in particular, to enhance parenting, seek reassurance, or find information prior to professional appointments. Wright, Matthai, and Meyer (2019) report online knowledge seeking increased women's confidence and self-assurance in decision-making for labor and birth. Though it has been suggested that women perhaps also use digital technologies to compensate for inadequate provider information and hurried appointments (Kraschnewski et al., 2014). Nevertheless, women enjoy the instantaneous accessibility of Web 2.0 tools, the ability to search for information online, and connect with other women 24/7 during pregnancy (Bjelke, Martinsson, Lendahls, \& Oscarsson, 2016).

Kane (2017) argues that social media is not a technology, but instead a possibility for action or "affordance." The evolvement of affordances enabled by the social media platforms ability to develop and innovate the technological infrastructure producing opportunities for diverse communication. Considered in this sense, healthcare bodies, maternity professionals, and stakeholders have an opportunity to utilize social media and begin delivering solutions to accommodate the changing nature of women's information seeking practices.

The aim of this article is to examine the literature and develop a deeper understanding of how social media may impact upon women, childbearing, and midwifery practice via six domains: (a) Global Influence, United Kingdom (UK) policy background and barriers to implementation; (b) Censorship of women; birth in the media, consumerism, and patriarchy; (c) Social construction of social media, identity, and networks; (d) Women's needs; the story and the narrative; (e) Evidence-based practice, shared decision-making and autonomy; and (f) Future service design.

\section{GLOBAL INFLUENCE, UK POLICY BACKGROUND AND BARRIERS TO IMPLEMENTATION}

Accessibility to information and communication technologies are a major global driver for government; increasing knowledge rights and opportunities for social, economic, and political empowerment (United Nations [UN], 2005). The UN (2016), in partnership with civil and administration bodies deliver on the Sustainable Development Goals (SDGs), a number of which relate to reducing equity experienced in women's health and empowerment. Reducing the digital literacy gap is crucial to closing the digital gender gap and achieving several SDG's. For example; SDG 4, which seeks to "ensure inclusive and equitable quality education and to promote lifelong learning opportunities for all" (UN, 2016, p. 5). Further evidence also advocates the use of mobile health, also known as mhealth, to mobilize knowledge and enhance health communication in the developing world (Free et al., 2010; Hall, Fottrell, Wilkinson, \& Byass, 2014; Waegemann, 2010).

In the UK, various government reports highlight the role of technology in improving health outcomes and delivering financial improvement to the National Health Service (NHS; Cabinet Office, 2017; DH, 2017; Public Health England, 2014). Briefings from The King's Fund however, suggest that this strategy has been fraught with confusing messages, unrealistic targets and lack of funding (Honeyman, Dunn, \& McKenna, 2016). Others highlight that NHS providers as a whole have been slow to adopt digital innovation, despite individual and professional groups harnessing opportunities to effect powerful change (McCrea, 2014). The analysis of literature provided by Koteyko, Hunt, and Gunter (2015) highlight multiple and complex sociological factors impacting on social media and healthcare behaviors. 
They suggest that an evolutionary framework, which integrates familiar health maintenance activities into social media will enhance the reconfiguration of healthcare systems. Furthermore, they discuss healthcare provider anxiety over "vulnerability" of lay users (in our context, women) exposed to all forms of knowledge both medical and alternative to be real concerns for culturally paternalistic healthcare systems bound by regulation and policy. Deeply engrained medical dominance presents further ethico-legal issues when realizing the potential of social media for women's empowerment. All these issues may subsequently act as barriers to implementation. To arrive at a deeper understanding of these issues, we explore the underlying portrayal of women in the media in via Domain 2.

\section{CENSORSHIP OF WOMEN; PATERNALISM, CONSUMERISM, AND BIRTH IN THE MEDIA}

\section{Censorship of Women}

Ferguson (2014) synthesizes a negative critique about social media and the impacts on women's empowerment suggesting an obsession with "youth and femininity" and a lack of women's perspective and individuality (Ferguson, 2014, p. 678). Media themes relating to obesity, visceral culture, and the maternal body can be regularly observed under the spotlight. One such example being the public shaming of a mother branded a "tramp" for nursing her baby in the street (BBC, 2014). Within her 2012 essay collection, artist and essayist, Buller, explores the censorship and discrimination of the pre- and postnatal maternal body (Buller, 2012). Here, she suggests that social perceptions in relation to the maternal body navigate complex extremes from scandalous and invisible to highly celebrated. In so doing, a generation of women are manufactured, who must explore deeply challenging internal reflection in order to attempt to reconcile these pressures (Mayoh, 2019). It is suggested these lead women to perceive that they must choose whether to act as either an "activist against" or "pacifist to" the pressures they experience. In turn, it is proposed that this may subconsciously affect their internal sense of power and agency which, in relation to health and wellness is key to understanding notions of women's submissive or seemingly insubordinate health behaviors during pregnancy and birth.

\section{Paternalism}

Adding to this complexity is patriarchal political influence and abuse for economic and political gain. One example of this can be seen in recent UK journalism, which suggest that midwives' pursuit of "normal" birth endangers women and causes feelings of failure (Borland, 2017; Smyth, 2017). These same writings also blame midwifery mistakes for episodes of stillbirth. Consequently, an increased fear in women and midwives due to such technocratic control both undermines and undervalues evidence-based physiological birthing processes in mainstream publics. This could be described as "abhorrent," given the quantity of high-quality evidence available in support of safe birth in midwifery-led settings (Hollowell, 2011; Hollowell et al., 2015; NICE, 2014). Much can be gleaned about societal response to this biased journalism from the subsequent running commentary on social media. Women and midwives may as a result, use these threads as suitable proxy for individual truths when in reality much of this may boil down to the consumerist rhetoric of a posttruth era. Therefore, the sociological and psychological impacts for maternity care are potentially vast.

\section{Birth in the Media}

To compound this paternalistic undercurrent, Morris and McInerney (2010) highlight the interplay between technology, medical interventions, and the powerlessness of birthing women in television shows aired in the United States of America. Perpetuating the notion presented by DeJoy (2010) of birth as a dangerous life-threatening event. Alternatively, Luce et al. (2016) offer insight about why women experience fear and anticipate negative outcomes in childbirth; that birth is missing as an everyday event in families and communities. Seemingly, women's realistic knowledge about pregnancy and childbirth may no longer be passed readily from generation to generation, leading women to turn to the Internet and media to learn about childbirth (Liechty, Coyne, Collier, \& Sharp, 2017). Instead, women may witness visual and verbal commentary which broadcasts over-medicalized birth, complexity and pain, leading to increased fear and unrealistic perceptions (Fleming et al, 2014; Hauck, Fenwick, Downie, \& Butt, 2007). Gleeson, Craswell, and Jones (2018) also suggest that this change may be due to the shifting macro structures within society, such as traditional gendered roles, the demise 
of the extended family and restructure of modular families. This presents an opportunity for the tools of Web 2.0 to be utilized by healthcare professionals to pro-actively support and engage women in their knowledge of childbirth (Liechty et al., 2017; Nolan, Hendricks, Williamson, \& Ferguson, 2018) but further to this campaign for more nuanced journalism generally.

\section{Consumerism}

Research demonstrates midwives share concerns about digital technologies and the advancement of knowledge; querying the quantity and reliability of accessible information and poor interpretation by women (Bjelke et al., 2016; Johnsen, 2014). Thus, contributing to the disempowerment of women. However, this is a complex issue, because the medicalization of childbirth has also witnessed technology updates such as the Pinard horn stethoscope being replaced by the digital fetal monitoring doppler. The Internet has subsequently been used as a consumerist marketing tool to influence culture and society to endorse the unsafe use of home dopplers (Lagan, Sinclair, \& George Kernohan, 2010). Here, women can hear their own baby's heartbeat, unaware that a reassuringly rhythmic beat is not necessarily representative of a healthy baby. Midwives blame this important knowledge gap on the Internet, and social media in particular, for producing self-proclaimed expert communities of unreliable information (Johnsen, 2014). This example of consumerism and maintenance of a medical paradigm may both diminish women's intimate knowing of their pregnant body and devalue the professional skills of midwives. In addition, one could argue that this outlook breaches the NMC's (2018) code of conduct, which advocates for women's freedom and agency. Understanding the complexities at play here is crucial. Blame cannot be easily apportioned in a consumerist society. While the media may at times undermine midwifery professionalism, it also promotes the importance of campaigns like Each Baby Counts (Royal College of Obstetricians and Gynaecologists, 2015), both of which arguably reside within a paternalistic defensive practice framework. Consequently, long standing midwifery principles may become harder to maintain. A midwifery focus on using social media to support women's wellness, birthing knowledge, and communications with healthcare may in turn counter some of these complexities (Nolan et al., 2018).

\section{SOCIAL CONSTRUCTION OF SOCIAL MEDIA, IDENTITY, AND NETWORKS}

Despite the seemingly negative critique of social media and the impacts on women presented in the last domain, this domain explores how online identity and networks provide a powerful force to be reckoned. Stark and Fins (2012) provide a poetic and somewhat beautiful account of the reciprocal dance between the authors and readers engaged in the posts, blogs, videos, and tweets on social media. They describe the social media construct.

Constituent exchanges, conversational threads, pronouncements, and postings, may be conceptualized as less a static repository of isolated comments than an evolving artefact of social construction, built by authors and readers. It is a symphonic piece, never a solo performance, in which truth, fiction, fact, and emotion come together to create something no single player could perform as progressive exchanges morph meanings from start to finish. (Stark \& Fins, 2012, p. 1)

This description identifies the complexity of social media as a concept in terms of production especially related to healthcare, in that it is never fixed. In fact, sociotechnical boundaries are often blurred when attempting to decipher cause and effect, structure and agency (Kierans, Bell, \& Kingdon, 2016). The ability to understand social media as a contemporary dimension of modern society, applied to trends in childbirth and parenting (e.g., hypnobirthing, birth experience and discussion about medical intervention), are suggested to be as much about western neo-liberal capitalism as CBPP enterprise (Fuchs, 2012). As such, the lines between "producers" and "consumers" of knowledge, goods, and services may have become somewhat blurred. Wright et al. (2019) suggest a "greater clinical understanding of social media consumption and its influences" is necessary to inform future practice (Wright et al., 2019, p.1).

Bijker, Hughes, and Pinch (2012) describe various sociological theories such as the Actor Network Theory (ANT), the Social Construction of Technology (SCOT), and Large-Scale Technological Systems (LTS) applied to digital technologies and human action. Digital technologies alter individual powers to act and where and when they act. Yet these authors suggest that conventional structuring factors such as economic indices, ethnic background, and gender can be hidden in digital community and society. This therefore makes it more difficult to interpret. In this respect, social media could be viewed as a driver for human inclusion and mutuality but also a double-edged sword, as it has 
the potential to minimize important social and cultural norms. For example, Rogers' (2015) suggests that the majority of "mummy bloggers" are heterosexual, White, middle class mothers and therefore subvert the diversity and experience of motherhood, which could lead to the marginalization of women who do not conform or fit suggested ideals. This discussion about online identity and networks may help develop understanding of the empowered woman as a producer and consumer of knowledge which, via domain 4 , may subsequently transform knowledge seeking practices.

\section{WOMEN'S NEEDS; THE STORY AND THE NARRATIVE}

Birth culture and experience have been placed at the top of the agenda especially where perinatal and postnatal mental health are concerned, driving social media campaigns like the Mental Health Alliance "Everyone's Business" (Das, 2018; Everyone's Business Maternal Mental Health, 2014; MBRRACE, 2015). However, social media sites also offer a wealth of information which can inform both policy and practice.

Static Internet websites, provided by institutional bodies and charities, offer repositories of information about childbirth and parenting, of which women are reported to use (Hearn et al., 2013). Daneback and Plantin's (2014) literature review outlines how websites focus on wide ranging specific subjects such as pregnancy loss, infertility, breastfeeding, and parents of children with disabilities. Yet it has been suggested that content specific websites have been medically positioned and lack the social or emotional aspects that come with certain diagnoses (Himmel, Meyer, Kochen, \& Michelmann, 2005; Zaidman-Zait \& Jamieson, 2007). More recent research, which attempt to understand the influence of narratives on social media and have since surfaced (Sanders \& Crozier, 2018).

Social sites of Web 2.0, for example, discussion forums found on Facebook and Mumsnet, enable women the opportunity to interact and share experiences and offer advice anonymously with other women (Baker \& Yang, 2018; Pedersen, 2014, 2016). In particular, they support women to establish "the norm" without experiencing embarrassment, stigma, and judgment (Pedersen \& Lupton, 2016). Litchman et al. (2019) explore the value of personal blogs, particularly the reproductive health experiences of women with disabilities. These blogs offer important insight into the challenges faced, and while providing peer support to women they may also be used to educate students and healthcare professionals about unmet needs, stigma, and stereotyping experienced by these groups.

In her work, "Birth Stories," funded by the British Academy, Das (2018) examines how the media shapes intricate birth knowledge, how women access and interpret it and form expectations for birth. Das explains that "these forms of communication, may work to selectively silence and marginalize, or highlight and bring to relief, the voices and experiences of others" (Das, 2018, p. 21). Das refers to social media forums as "baggageladen subjects of intensive motherhood" explaining the subtle contrast between two narratives. One empowering - supportive of feminist notions of woman-centerd care led by midwives respectful of the physiology of birth, and as Kitzinger (2011) asserts the power of the women who has revealed her intimate passage to motherhood. The other narrative features more frequently and with precensored (mediated) "trigger" warnings describes disempowering "horror stories" of traumatic birth, which may expose women to prolonged physical and psychological damage. Johnson's (2014) variation on this concept proposes that social media transforms the knowledge seeking practices of mothers while promoting vital "intimate mothering publics." In this context, midwives may be best placed to support women by opening up a space for these types of conversation. Though midwives may challenge how this opportunity could arise, given some of the bureaucratic and time management challenges apparent in maternity services.

Rogers (2015) illuminates how online actors construct their maternal identities to "subvert the scripts of their families, cultures and nations in their quest for self-knowledge, agency and artistic expression" (Rogers, 2015 , p. 259) coining the term "maternal essayists" as a form of maternal scholarship. By doing so, these online communicators rework traditional narratives of motherhood and reconcile pressures and trends of parenting to develop new concepts for modern women and society. However, the work of Nixon, Rawal, and Funk (2016) points to concerns over the impersonality of online communities, where distance can create "coldness" and the success of groups depends on the value attitudinal behaviors of the individuals posting within it. This is concerning, as those seeking support and empathy in relation to matters such as stillbirth or mental health may be more vulnerable to unkind, and emotionless comments. The lack of physicality, ability to read body language and tone of voice may also greatly impact on contextualized meaning. 
In this way, social media could present as a dangerous place for women's emotional health and wellbeing.

\section{EVIDENCE-BASED PRACTICE, SHARED DECISION-MAKING AND AUTONOMY}

The importance of women receiving explicit as well as experimental knowledge is of course paramount, and research reiterates the frequency with which women routinely draw on professional sources of knowledge to support their decision-making. For example, according to Johnsen (2014), midwives offer important verification, a professional viewpoint and processing opportunities for the childbearing woman. This suggests that the traditional "woman-professional" relationship has remained intact thus far.

While it is possible for individuals to seek academic research, they may lack adequate skills in synthesis or the ability to ascertain the quality of evidence, leading to inaccurate conclusions, inappropriate decisions and management of care (Lagan et al., 2010). Equally, individuals may use social media to process their own feelings and use this as a proxy for "truth" because it resonates so powerfully within them. These issues may present as ethical dilemmas for midwives situated in a "rights-based" approach to care which promotes the views, beliefs, and values of women and families, particularly regarding the principals of advocacy, choice, and informed consent.

Romano, Gerber, and Andrews (2010) thought provoking paper about decision-making in relation to women exploring Vaginal Birth after Caesarean Section (VBAC) highlights the importance of the e-Patients White Paper (Ferguson \& e-Patients Scholars Working Group, 2007). The latter challenge the traditional topdown dissemination of information, suggesting that it leads to poorer outcomes and compromises care satisfaction and autonomy. Romano et al. present Internet VBAC forums as a safe space for women to explore and understand the benefits and risks associated with VBAC. They do so through a cohesive community of women, who share the desire for experiential knowledge and understanding from others who have successfully negotiated what they perceive to be highly paternalistic services, to achieve a VBAC.

Gregg and Driscoll (2008) offer insights about presence, intimacy, and communities. Digital literacies and intimacies being fostered among friends in online environments may in fact offer the best protection against the invasive dangers presumed to originate outside those communities, including with those who readily seek to turn the leisure choices of the young into commodifiable skills for a global economy (Gregg \& Driscoll, 2008, p. 129).

Social media technologies or "affordances" could offer a protective factor to the commodification of women and the financial gains of medicalized birth.

Mol's (2008) concept of autonomy can also be well applied to the example of VBAC forums and other similar social media enterprises. In doing so, rather than offer increased choice, human connectivity and interdependence may further restrict individuals due to societal influences, mediation, and the pressure to conform and perform. The application of cultural norms. Likewise, in Stark and Fins (2012) previous poetic description, Gregg and Driscoll (2008) discuss online culture and the constructs of identity and community by framing "presence" as not only person-centerd interaction but in the tenacious subtext of individual tastes and/or operations in the creation (production) of online flair and eloquence. In this sense, presence resides within the habitat (community) of the network. That habitat then creates meaning. Presented in this way, Mol's argument is clearautonomy is a myth.

\section{FUTURE SERVICE DESIGN}

The literature synthesized within this article suggests that the Internet and the tools of Web 2.0 are being used by women and families over the childbirth continuum. This may likely lead to the transformation of the current client-professional relationship. More than a decade ago, Gregg and Driscoll (2008) called for all maternity services to have a digital media strategy. While NHS Trusts are now likely to have a social media policy which is underpinned by regulatory bodies and addresses both professional conduct and client confidentiality matters (NMC, 2019), there is seemingly a paucity of strategic innovations which harness the full potential of using social media. The 2016 Better Births Report advocates that technology should be embedded into routine maternity services enhancing accessibility to individualized evidence-based information for women (Cumberlege, 2016). However, this falls short in offering a descriptive account of what this might entail. Additionally, individual midwives may not wholly understand the concepts surrounding the Internet and social media usage. This 
remains a concern for those tasked with digital innovation and equipping the profession for the future workplace.

Despite this, examples of innovation can be found. Basildon and Thurrock University Hospitals launched Maternity Direct+ in 2015. This particular innovation comprised a Trust based Facebook page, where women could confidentially contact a midwife online, with nonurgent questions relating to their pregnancy (Tranter \& McGraw, 2017). This online space was also used to promote public health issues and advertise trust specific initiatives. Unpublished outcomes suggested a high level of demand and user satisfaction for the service. This initiative also overcomes systemic social media education issues by harnessing the skills of a specific named Internet midwife, who would have the capability to educate others.

Service providers utilizing local contextual information to enhance service delivery, for example; Trusts operating in areas of poverty and high levels of smoking are often part of national trials such as the AFFIRM study which aims to reduce stillbirth (Norman, 2017). These Trusts would be able to use social media to broadcast often-unknown research activities to women. Utilizing social media in this way could in turn, raise the profile of services that often come under attack in the media. The Maternity Direct+ example, in particular may provide a safe area for women who have been using forums to explore the lived-experience of other women, to speak to a midwife, ask questions, and reconcile their thoughts around birth.

Overall, social media has the potential to reduce secondary care contacts for generalized, nonurgent pregnancy questions while also supporting women with individualized answers (Himmel et al., 2005). In addition, barriers to care, such as poverty, lack of finances or childcare to attend appointments, geographical issues and time efficiency for midwives may be reduced with the use of social media (Daneback \& Plantin, 2014). Chan and Chen (2019) discuss the potential for social media and mhealth apps to support women's physical health including behavior change in relation to diet and lifestyle, control of gestational diabetes mellitus and asthma with a moderate to large effect size. Stephenson, Hetherington, Dodd, Mathews, and Tough (2019) discuss the value of social media, Facebook in particular in communicating and retaining consented cohort participants for pregnancy research studies which may add a further advantage in gaining important long-term evidence to support future practice.

\section{CONCLUSIONS}

Via six domains, this article offers new insights into the technological, social, and cultural mediation of childbirth through Web 2.0. Here, the relevant wider literature drawn together is presented narratively, and synthesized through the lens of western culture. There has been a change in the way in which women find community and seek explicit, embodied, and experimental knowledge about childbirth. Yet the needs of modern women in relation to these issues may not be being met within the current framework of care. Maternity systems may therefore require enhanced funding and knowledge to include web-based education and training for midwives, so that innovative digital tools can be embraced to offer support which truly integrates woman-centerd experience and satisfaction into care. In so doing, any expanding crevasses between midwifery and the development of meaningful relationships with women may be curtailed.

\section{REFERENCES}

Baker, B., \& Yang, I. (2018). Social media as social support in pregnancy and the postpartum. Sexual \& Reproductive Healthcare, 17, 31-34. doi:10.1016/j.srhc.2018.05.003

BBC. (2014). Mum labelled 'tramp' for breastfeeding. Retrieved from http://www.bbc.co.uk/news/uk-england-stokestaffordshire-26519660

Benkler, Y. (2011). The unselfish gene. Harvard Business Review, 89(7), 76-85. Retrieved from https://hbr.org/ 2011/07/the-unselfish-gene

Bijker, W., Hughes, T., \& Pinch, T. (2012). The social construction of technological systems. Cambridge, MA: MIT Press.

Bjelke, M., Martinsson, A., Lendahls, L., \& Oscarsson, M. (2016). Using the Internet as a source of information during pregnancy - A descriptive cross-sectional study in Sweden. Midwifery, 40, 187191. doi:10.1016/j.midw.2016.06.020

Borland, S. (2017). Midwives' mistakes 'causing stillbirths'. Retrieved from http://www.dailymail.co.uk/ health/article-4623638/Midwives-mistakes-causingstillbirths.html

Buller, R. (2012). Reconciling art and mothering. Oxford, England: Routledge; Taylor \& Francis. 
Cabinet Office. (2017). Government transformation strategy - GOV.UK. Retrieved from https://www. gov.uk/government/publications/governmenttransformation-strategy-2017-to-2020/governmenttransformation-strategy

Chan, K., \& Chen, M. (2019). Effects of social media and mobile health apps on pregnancy care: Metaanalysis. JMIR Mhealth and Unhealth, 7(1), e11856. doi: $10.2196 / 11836$

Cumberlege, J. (2016). National maternity review [Ebook] (1st ed.). Retrieved from https://www.england.nhs.uk/wpcontent/uploads/2016/02/national-maternity-reviewreport.pdf

Daneback, K., \& Plantin, L. (2014). Research on parenthood and the Internet: Themes and trends. Cyberpsychology: Journal of Psychosocial Research On Cyberspace, 2(2). Retrieved from https://cyberpsychology.eu/article/view/4213/3255

Das, R. (2017). Speaking about birth: Visible and silenced narratives in online discussions of childbirth. Social Media + Society, 3(4), 205630511773575. doi:10.1177/2056305117735753

Das, R. (2018). The mediation of childbirth: 'Joyful' birthing and strategies of silencing on a Facebook discussion group. European Journal of Cultural Studies, 22, 495510. doi:10.1177/1367549417722094

DeJoy, S. (2010). "Midwives are nice, but. . . ": Perceptions of midwifery and childbirth in an undergraduate class. Journal of Midwifery \& Women's Health, 55(2), 117-123. doi:10.1016/j.jmwh.2009.05.009

Dekker, R., King, S., \& Lester, K. (2016). Social media and evidence-based maternity care: A cross-sectional survey study. The Journal of Perinatal Education, 25(2), 105115. doi:10.1891/1058-1243.25.2.105

Department of Health. (2016). Improving the quality and safety of patient care [Ebook]. London, England: Author. Retrieved from https://www.gov.uk/govern ment/uploads/system/uploads/attachment_data/file/508 385/40021_UKTI_Patient_Safety_brochure_final_ LR.pdf

Department of Health. (2017). Digital-first public health: Public health England's digital strategy - GOV.UK. Retrieved from https:/www.gov.uk/government/publications/ digital-first-public-health/digital-first-public-healthpublic-health-englands-digital-strategy

Everyone's Business Maternal Mental Health. (2014). Call to ACT [Ebook] (1st ed.). Retrieved from http://everyonesbusiness.org.uk/wp-content/uploads/ 2014/07/Call-to-ACT.pdf
Ferguson, S. (2014). Race, ethnicity, gender, and class + race, gender, sexuality, and social class: Dimensions of inequality (p. 658). London, England: Sage.

Ferguson, T., \& e-Patients Scholars Working Group. (2006). e-patients: How they can help us heal healthcare [Ebook]. Austin, TX: American Statesman. Retrieved from https://participatorymedicine.org/ePatient_White_Paper_with_Afterword.pdf

Fleming, S., Vandermause, R., \& Shaw, M. (2014). Firsttime mothers preparing for birthing in an electronic world: Internet and mobile phone technology. Journal of Reproductive and Infant Psychology, 32(3), 240-253. doi:10.1080/02646838.2014.886104

Free, C., Phillips, G., Felix, L., Galli, L., Patel, V., \& Edwards, P. (2010). The effectiveness of M-health technologies for improving health and health services: A systematic review protocol. BMC Research Notes, 3(1), 250. doi:10.1186/1756-0500-3-250

Frizzo-Barker, J., \& Chow-White, P. (2012). “There's an app for that" Mediating mobile moms and connected careerists through smartphones and networked individualism. Feminist Media Studies, 12(4), 580-589. doi:10.1080/14680777.2012.741876

Fuchs, C. (2012). Capitalism or information society? The fundamental question of the present structure of society. European Journal of Social Theory, 16(4), 413-434. doi: $10.1177 / 1368431012461432$

Gibson, L., \& Hanson, V. (2013). Digital motherhood. Proceedings of The SIGCHI Conference on Human Factors In Computing Systems - CHI '13, Paris, France. doi: $10.1145 / 2470654.2470700$

Gleeson, D., Craswell, A., \& Jones, C. (2018). Women's use of social networking sites related to childbearing: An integrative review. Women and Birth, 32, 294-302. doi:10.1016/j.wombi.2018.10.010

Gregg, M., \& Driscoll, C. (2008). Message me: Temporality, location and everyday technologies. Media International Australia, 128(1), 128-136. doi:10.1177/ $1329878 x 0812800116$

Hall, C., Fottrell, E., Wilkinson, S., \& Byass, P. (2014). Assessing the impact of mHealth interventions in low- and middle-income countries - what has been shown to work? Global Health Action, 7(1), 25606. doi:10.3402/gha.v7.25606

Hauck, Y., Fenwick, J., Downie, J., \& Butt, J. (2007). The influence of childbirth expectations on Western Australian women's perceptions of their birth experience. Midwifery, 23(3), 235-247. doi:10.1016/j.midw.2006. 02.002 
Hearn, L., Miller, M., \& Fletcher, A. (2013). Online healthy lifestyle support in the perinatal period: What do women want and do they use it? Australian Journal of Primary Health, 19(4), 313. doi:10.1071/py13039

Hill, M. (2017). Positive birth book: A new approach to pregnancy, birth and the early weeks. London, UK: Pinter \& Martin Ltd.

Himmel, W., Meyer, J., Kochen, M., \& Michelmann, H. (2005). Information needs and visitors' experience of an Internet expert forum on infertility. Journal of Medical Internet Research, 7(2), e20. doi:10.2196/jmir.7.2.e20

Hollowell, J. (2011). Birthplace programme overview: Background, component studies and summary of findings [Ebook] (1st ed.). Oxford, England: National institute for Health Research. Retrieved from https://www.npeu.ox.ac.uk/research/birthplaceprogramme- 110

Hollowell, J., Rowe, R., Townend, J., Knight, M., Li, Y., Linsell, L., \& Silverton, L. (2015). The Birthplace in England national prospective cohort study: Further analyses to enhance policy and service delivery decision-making for planned place of birth. Health Services and Delivery Research, 3(36), 1-264. doi:10.3310/hsdr03360

Honeyman, M., Dunn, P., \& McKenna, H. (2016). A digital NHS? An introduction to the digital agenda and plans for implementation [Ebook]. London, UK: The Kings Fund. Retrieved from https://www.kingsfund. org.uk/sites/default/files/field/field_publication_file/A_ digital_NHS_Kings_Fund_Sep_2016.pdf

International Confederation of Midwives. (2013). Global standards for Midwifery education [Ebook]. Hague, Netherlands: Author. Retrieved from https://www. internationalmidwives.org/

Jain, P., Koray, E., Carpenter, R., \& Roe, H. (2017). Tech tracker quarterly release: Q3 2017 [Ebook]. Paris, France: IPSOS. Retrieved from https://www. ipsos.com/sites/default/files/ct/publication/documents/ 2017-10/Ipsos_Connect_TechTracker_Q3_2017_0.pdf

Johnsen, H. (2014). The impact of internet use on the client-professional relationship: A comparative analysis. British Journal of Midwifery, 22(3), 188-193. doi:10.12968/bjom.2014.22.3.188

Johnson, S. (2014). ' Intimate mothering publics': Comparing face-to-face support groups and Internet use for women seeking information and advice in the transition to firsttime motherhood. Culture, Health \& Sexuality, 17(2), 237-251. doi:10.1080/13691058.2014.968807
Kane, G. (2017). The evolutionary implications of social media for organizational knowledge management. Information and Organization, 27(1), 37-46. doi:10.1016/j.infoandorg.2017.01.001

Kierans, C., Bell, K., \& Kingdon, C. (2016). Social and cultural perspectives on health, technology, and medicine (1st ed.). Abingdon, England: Routledge.

Kittur, A., Suh, B., \& Chi, E. (2008). Can you ever trust a wiki? Proceedings of The ACM 2008 Conference on computer supported cooperative work - CSCW '08, San Diego, CA. doi:10.1145/1460563.1460639

Kitzinger, S. (2011). Rediscovering birth. London, England: Pinter \& Martin.

Koteyko, N., Hunt, D., \& Gunter, B. (2015). Expectations in the field of the Internet and health: An analysis of claims about social networking sites in clinical literature. Sociology of Health \& Illness, 37(3), 468-484. doi:10.1111/1467-9566.12203

Kraschnewski, J., Chuang, C., Poole, E., Peyton, T., Blubaugh, I., Pauli, J., \& Reddy, M. (2014). Paging "Dr. Google": Does technology fill the gap created by the prenatal care visit structure? Qualitative focus group study with pregnant women. Journal of Medical Internet Research, 16(6), e147. doi:10.2196/jmir.3385

Lagan, B., Sinclair, M., \& George Kernohan, W. (2010). Internet use in pregnancy informs women's decision making: A web-based survey. Birth, 37(2), 106-115. doi:10.1111/j.1523-536x.2010.00390.x

Liechty, T., Coyne, S., Collier, K., \& Sharp, A. (2017). "It's just not very realistic": Perceptions of media among pregnant and postpartum women. Health Communication, 33(7), 851-859. doi:10.1080/10410236.2017.1315680

Litchman, M., Tran, M., Dearden, S., Guo, J., Simonsen, S., \& Clark, L. (2019). What women with disabilities write in personal blogs about pregnancy and early motherhood: Qualitative analysis of blogs. JMIR Pediatrics and Parenting, 2, e12355. Retrieved from https://pediatrics.jmir.org/2019/1/e12355/

Lucassen, T., \& Schraagen, J. (2010). Trust in Wikipedia. Proceedings of the 4th Workshop on Information Credibility - WICOW '10, Raleigh, CA. doi:10.1145/1772938.1772944

Luce, A., Cash, M., Hundley, V., Cheyne, H., van Teijlingen, E., \& Angell, C. (2016). "Is it realistic?" The portrayal of pregnancy and childbirth in the media. BMC Pregnancy and Childbirth, 16(1), 40. doi:10.1186/s12884016-0827-x 
Lupton, D. (2016). The use and value of digital media for information about pregnancy and early motherhood: A focus group study. BMC Pregnancy and Childbirth, 16(1), 171. doi:10.1186/s12884-016-0971-3

Lupton, D., \& Pedersen, S. (2016). An Australian survey of women's use of pregnancy and parenting apps. Retrieved from http://www.womenandbirth.org/article/S18715192(16)00032-9/fulltext

Mayoh, J. (2019). Perfect pregnancy? Pregnant bodies, digital leisure and the presentation of self. Leisure Studies, 38(2), 204-217. doi:10.1080/02614367.2018.1562492

MBRRACE. (2015). Reports: MBRRACE-UK, NPEU. Retrieved from https:/www.npeu.ox.ac.uk/mbrrace$\mathrm{uk} /$ reports

McCrea, J. (2014). On the brink of SoMething special? The first comprehensive analysis of social media in the NHS [Ebook]. London, UK: JB McCrea Ltd. Retrieved from http://jbmccrea.com/wordpress/wpcontent/uploads/2014/12/State-of-Social-Media-inthe-NHS.pdf

Mol, A. (2008). The logic of care. London, England: Routledge.

Morris, T., \& McInerney, K. (2010). Media representations of pregnancy and childbirth: An analysis of reality television programs in the United States. Birth, 37(2), 134140. doi:10.1111/j.1523-536x.2010.00393.x

National Institute for Health and Career Excellence. (2014). Intrapartum care: Care of healthy women and their babies during childbirth, Guidance and guidelines, NICE. Retrieved from http://www.nice.org.uk/guidance/cg190

Nixon, P., Rawal, R., \& Funk, A. (2016). Digital media usage across the life course. London, UK: Routledge.

Nolan, S., Hendricks, J., Williamson, M., \& Ferguson, S. (2018). Social networking sites (SNS) as a tool for midwives to enhance social capital for adolescent mothers. Midwifery, 62, 119-127. doi:10.1016/j.midw.2018.03.022

Norman, J. (2017). The AFFIRM study. Retrieved from https://www.ed.ac.uk/centre-reproductive-health/theaffirm-study

Nursing and Midwifery Council. (2018). The code online. Retrieved from http://www.nmc.org.uk/ standards/code/read-the-code-online/

Nursing and Midwifery Council. (2019). Guidance on using social media responsibly [Ebook]. London, England: Author. Retrieved from https://www. nmc.org.uk/globalassets/sitedocuments/nmcpublications/social-media-guidance.pdf

Pedersen, S. (2014). Is it Friday yet? Mothers talking about sex online. Retrieved from https://cyber psychology.eu/article/view/4307/3356
Pedersen, S. (2016). The good, the bad and the 'good enough' mother on the UK parenting forum Mumsnet. Women's Studies International Forum, 59, 32-38. doi:10.1016/j.wsif.2016.09.004

Pedersen, S., \& Lupton, D. (2016). 'What are you feeling right now?' Communities of maternal feeling on Mumsnet. Emotion, Space and Society, 26, 57-63. doi:10.1016/j.emospa.2016.05.001

Phillippi, J., \& Buxton, M. (2010). Web 2.0: Easy tools for busy clinicians. Journal of Midwifery \& Women's Health, 55(5), 472-476. doi:10.1016/j.jmwh.2010.05.009

Public Health England. (2014). Knowledge strategy: Harnessing the power of information to improve the public's health - GOV.UK. Retrieved from https:// www.gov.uk/government/publications/knowledgestrategy-harnessing-the-power-of-information-toimprove-the-publics-health

Rogers, M. (2015). Beyond blogging: How mothers use creative non-fiction techniques in digital environments to dislodge the mask of motherhood. Journal of Family Studies, 21(3), 248-260. doi:10.1080/13229400.2015.1074932

Romano, A., Gerber, H., \& Andrews, D. (2010). Social media, power, and the future of VBAC. Journal of Perinatal Education, 19(3), 43-52. doi:10.1624/105812410x514431

Royal College of Midwives. (2014). High quality midwifery care [Ebook] (1st ed.). London, UK: Author. Retrieved from https://www.rcm.org.uk/media/2354/high-quality-mid wifery-care.pdf

Royal College of Obstetricians and Gynaecologists. (2015). Each baby counts 2015 full report. Retrieved from https:// www.rcog.org.uk/en/guidelines-research-services/ audit-quality-improvement/each-baby-counts/ebc2015-report/

Smyth, C. (2017). Midwives back down on natural childbirth. Retrieved from https://www.thetimes.co.uk/ article/midwives-back-down-on-natural-childbirth$2 \mathrm{f} 78 \mathrm{~d} 65 \mathrm{ng}$

Stark, M., \& Fins, J. (2012). The self, social media, and social construction. The American Journal of Bioethics, 12(10), 38-39. doi:10.1080/15265161.2012.708094

Statista. (2019a). Global digital population 2019. Retrieved from https:/www.statista.com/statistics/ 617136/digital-population-worldwide/

Statista. (2019b). Global social media ranking 2019. Retrieved from https://www.statista.com/statistics/272014/globalsocial-networks-ranked-by-number-of-users/

Stephenson, N., Hetherington, E., Dodd, S., Mathews, A., \& Tough, S. (2019). Mitigation of participant loss to 
follow-up using Facebook: All our families longitudinal pregnancy cohort. Journal of Medical Internet Research, 21, e10441. doi:10.2196/10441. Retrieved from https://www.jmir.org/2019/2/e10441/

Tranter, R., \& McGraw, C. (2017). Integrating social media into routine midwifery services: Maternity Direct+. British Journal of Midwifery, 25(7), 458-464. doi:10.12968/bjom.2017.25.7.458

United Nations. (2005). The World Summit on the information society; Tunis commitment. Retrieved from http://www. itu.int/net/wsis/docs2/tunis/off/7.html

United Nations. (2016). Goal 4: Sustainable development knowledge platform. Retrieved from https://sustainabledevelopment.un.org/sdg4

Ventola, L. (2014). Social media and health care professionals: Benefits, risks, and best practices. Pharmacy and Therapeutics, 39(7), 491-520. Retrieved from https://www.ncbi.nlm.nih.gov/pmc/articles/PMC 4103576/

Waegemann, C. (2010). mHealth: The next generation of telemedicine? Telemedicine and E-Health, 16(1), 23-25. doi:10.1089/tmj.2010.9990

Wallwiener, S., Müller, M., Doster, A., Laserer, W., Reck, C., Pauluschke-Fröhlich, J., . . . Wallwiener, M. (2016). Pregnancy eHealth and mhealth: User proportions and characteristics of pregnant women using eebbased information sources - A cross-sectional study. Archives of Gynecology and Obstetrics, 294(5), 937-944. doi:10.1007/s00404-016-4093-y

Web 2.0. (2019). In Dictionary.com. Retrieved from https:// www.dictionary.com/browse/web-2-0
World Health Organization. (2018). Recommendations on Intrapartum care for a positive childbirth experience. Geneva, Switzerland: Author.

Wright, E., Matthai, M., \& Meyer, E. (2019). The Influence of social media on intrapartum decision making. The Journal of Perinatal \& Neonatal Nursing, 1, 1-10. doi:10.1097/jpn.0000000000000377

Zaidman-Zait, A., \& Jamieson, J. (2007). Providing web-based support for families of infants and young children with established disabilities. Infants \& Young Children, 20(1), 11-25. doi:10.1097/00001163-200701000-00003

Disclosure. The authors have no relevant financial interest or affiliations with any commercial interests related to the subjects discussed within this article.

Funding. The author(s) received no specific grant or financial support for the research, authorship, and/or publication of this article.

Correspondence regarding this article should be directed to Hannah Tizard, BSc Midwifery, MA Midwifery Student at University of Central Lancashire, Meadow Vale, Beech Road, Elswick, Nr Preston, Lancashire, PR4 3YB. E-mail: hrtizard@uclan.ac.uk

Hannah Tizard, BSc Midwifery, MA Midwifery Student at University of Central Lancashire, Elswick, Nr Preston, Lancashire, England.

Sally Pezaro, PhD, Faculty of Health and Life Sciences, Coventry University, Coventry, England. 